tion involves also the endometrium or the uterine appendages. Chronic cervicitis of itself does not cause irregular uterine haemorrhage or pain.

It is when we consider the complications which may be consequent upon chronic cervicitis that the importance of the condition is realized. The cervix has been described as the tonsil of the pelvis, and it may act as a focus of infection. The experimental work of Laura Moench has shown that organisms grown from the chronically infected cervical glands of patients suffering from arthritis will produce joint lesions in rabbits, and culturally these organisms are identical with the anaerobic streptococci found in patients suffering from arthritis.

It is known that puerperal pyosalpinx and peritonitis may follow in patients suffering from chronic cervicitis of gonococcal and streptococcal origin. Finally, cervical trauma and cervical erosion may be associated with malig. nant disease. Bailey has recently reported upon the examination of 850 specimens of the cervix uteri in a paper entitled "An inquiry into the basic cause of cervical cancer; the pathology of cervicitis (cervical erosion) and the rclation between cervicitis and cancer of the cervix," in which he was able to trace the changes from erosion to maliguant disease.

\section{THE PATHOLOGY OF CHRONIC CERVICITIS.:} BY

GILBERT I. STRACHAN, M.D., M.R.C.P., F.R.C.S., ASSISTANT GYNAECOLOGIST, CARDIFF ROYAI INFIRMARY; FIRST ASSISTANT TO THE PROFESSOR OF OBSTETRICS AND GYNAECOLOGY, WELSH NATIONAL SCHOOL OF MEDICINE.

Chronic infection of the cervix is by far the most common lesion met with in gynaecological practice. Authorities differ only slightly in their estimates of its frequency, and it is safe to say that, alone or in combination with other lesions, it is present in from 70 to 85 per cent. of all patients seen. British gynaecologists have not given this lesion the attention that it merited, although the recent exhaustive research by $\mathbf{K}$. V. Bailey ${ }^{1}$ of Manchester is a most important contribution to the subject. In America and on the Continent, on the other hand, great attention lias been paid to the condition in recent years, and a rery extensive literature has grown round the subject.

The condition has received many names, such as cervical endometritis, ectropion of the cervix, cervical erosion, cervical catarrh, proliferative adenoma (B. P. Watson ${ }^{5}$ ), pseudo-adenoma (Eden and Lockyer ${ }^{2}$ ), cystic disease of the eervix, chronic cervicitis $\left(\right.$ Moench $\left.^{4}\right)$, and several others. Some of these names are giren to different appearances met with at different stages of the disease, while others are based on erroncous ideas of the pathology. The condition is found most commonly in women who have borne children; less commonly it is found in nulliparae; and less commonly still is it present in virgins.

\section{Structure of the Cervix.}

The structure of the cervix is important in this respect. It is covered on its raginal aspect by stratified squamous epithelium, which contains no glands and which is continuous with the general squamous lining of the ragina. This squamous epithelium is in its deeper basal layer composed of cylindrical cells; superficial to this the main substance of the epithelium is composed of several layers of polygonal "prickle" cells, while the superficial laver or two are composed of flat cells, which are cast off from time to time. From the cylindrical layer are produced by cell division the more superficial layers.

At the external os the squamous epithelium suddenly changes to a high columnar-celled epithelium, with decply placed nuclei. At numerous sites this epithelium is invaginated dceply into the mucosa, and into the innermost muscular layers of the cervix, to form compound racemose glands. The secretion from these glands and from the epithelium is thick, mucoid, and viscous, and forms the * A paper read in the Section of Obstetrics and Gynaecology at the
Manchester Meeting of the British Medical Association in opening a
discussion on chronie cervicitis. The paper was illustrated by lantern
slides showing the conditions described. characteristic cervical secretion. Deep to the epithelium on both aspects of the cervix is a scanty stroma which contains few cells, and which merges into the fibro-muscular substance of the cervix.

The high columnar epithelium lining the cervical canal can be followed up to the internal os, when the appearance again suddenly changes as the uterine cavity is reached. Here the epithelium is similar but not so high, the glandular depressions are simple tubules, and the stroma is thick and cellular.

Between these two epithelium-covered surfaces of the cervix is the main muscular and fibrous structure of the viscus. The muscular layers are described as three-an outer and an inner, both longitudinal, and an intermediate one, circular in direction-but in an ordinary section it is difficult to see any regular arrangement of this sort. Fibrous tissue strands lie between the muscular bundles, and thick-walled blood vessels and smailer endotheliumlined lymphatic spaces are also present.

The anatomical relations of the cervix are important from tho point of view of its pathology. Above it is continuons with the corpus uteri, and the intermuscular lymphatic spaces of the two communicate. It lies embedded in the pelvic cellular tissue, which stretches out on each side at the bases of the broad ligaments; posteriorly this cellular tissue is incorporated in the utero-sacral ligaments, which are attached to the sacrum on each side of the rectum, while anteriorly the less marked utero-vesical ligaments comnect the cervix with the bladder.

\section{The Infective Process.}

The essential lesion in cervicitis is irritation produced by infection, and this may be brought about in several ways, but the most usual mechanism is chronic pyogenic infection after laceration of the cervix at childbirth. It has to be understood that the extent of the laceration matters not at all; it is the incidence and degree of infection of even a small lacerated surface that counts. The ccinditions after labour rather predispose to infection. The cervix is patulous, lacerated, and bruised, with the vagina batlied in alkaline lochia instead of the normal acid sccretion, and in this way the normal resistance to infection is definitely impaired.

The most commonly found organisms in these cases aro the staphylococcus, streptococcus, and $B$. coli communis, but the gonococcus is responsible in a certain proportion of cases. In cervicitis occurring in nulliparae the gonococcus is a more common agent, and here it exercises its wellknown ability to penetrate and infect an intact mucous surface. It is very difficult to estimato the exact proportion of all cases which are of gonococcal origin, as the gonococcus soon becomes reinforced and masked by a mixed pyogenic infection, and also tends to disappear into the depths of glandular acini, and so is not obvious in swabs from the cervical canal. It is probable, in our cpinion, that the incidence of gonorrhoea as a causative agent in the production of cervicitis is exaggerated.

As a result of infection the changes of inflammation soon appear. While in some cases the inflammation may be acute in the early stages, it is usually only in the late chronic stage, which is discussed here, that the condition is first seen. But it is more than probable that the majority of cases are chronic in type from the onset.

There is oedema of the subepithelial stroma with outpouring of lymphocytes and plasma cells, especially round the blood ressels and the glands, and under the surface epithelium. The blood vessels dilate, the surface columnar and glandular epithelium becomes irritated, so that glandular hypertrophy and distension occur, and the cervical secretion becomes increased in amount and of a muco-purulent appearance from mixture with inflammatory products. This increased inflammatory cervical secretion is known as leucorrhoca. It always retains its thick, viscous tenacity, and it is to be emphasized that, in general, leucorrhoea is almost aluays a sign of cervical infection. Partly as a result of maceration by continual leucorrhoeal discharge, partly by being raised and devitalized by subepithelial oedema, and partly on account of trauma, a plaque of squamous epithelium surrounding the extemal os beconres separated and cast off in the discharge, 
and a raw surface of varying extent is now left wholly or partly surrounding the external os. The columnar epithelium from the cervical canal, being more resistant, is seldom affected in this manner; on the contrary, it is usually stimulated to grow outwards and cover over the raw surface, so that after a time the area round the external os becomes covered by columnar epithelium, which carries with it in its outgrowth cervical racemose glands. This area has a red, raspberry appearance, and the name "cervical erosion" is given to it. It was to this condition of outerowing endocervical epithelium and glands that Eden and Lockyer gave the name of "pseudoadenoma."

This erosion is not an ulcer and it is not a granulating patch; it is an epithelium-covered surface, although there is often a breach of continuity hetween the two types of epithelium at the periphery of the erosion. In the "congenital erosion" this condition of extension of glandular tissue on to the portio is also found, but this is usually regarded as a persistence of a foetal condition, although some obscrvers (Bailey) find inflammatory changes.

If the surface is smooth and the glands few the erosion is called "simple"; if the glands are numerous and dilated, the surface is rough, and the condition is called a "follicular erosion"; while if the glands are numerous but run mostly at right angles to the surface, numerous papillae project upwards between the glands, and it is known as a "papillary eresion." Occasionally these papillae grow to a large size, and constitute the single or multiple mucous polypi often found in this condition. These subdivisions are, however, artificial and unnecessary, and should be discarded.

If the cervix should be definitely lacerated, especially if bilaterally lacerated, it tends to become everted, partly by muscular action and partly as the result of inflammatory infiltration, so that the congested and thick endocervical mucosa is exposed to view. The name "ectropion" is given to this condition of eversion of the endocervical mucosa.

It has to be remembered, then, that the occurrence of erosion marks the first effort at healing on the part of the infected cervix by the covering over of the raw surface by epithelium. After a time the displaced squamous epithelium makes an attempt to reinstate itself. The basal germinal layer grows inwards and insinuates itself beneath the covering columnar epithelium. By cell division more superficial layers of cells are formed, and, with this process continuing, the columnar epithelium may finally be cast off from the eroded surface and confined to its normal bounds.

But prior to this the infection seldom remains limited to the mucosa; usually the fibro-muscular substance of the cervix has also become infected, so that chronic inflammatory hypertrophy is seen, and this, after the process subsides, may be succeeded by fibrosis and atrophy, so that the cervix is finally reduced to a hard nodular condition whose everted lips are shrunken and may be flush with the vaginal vault. Because of the frequency with which the substance of the cervix is infected in this way Moench suggests the appropriate name of "cervicitis" for the condition.

When the squamous epithelium displaces the columnar cells, the racemose glands of the latter are left in situ, and their ducts usually become occluded by blockage by epithelium, by blockage by inspissated secretion, or by periglandular fibrosis, and one of two things usually happens. Most commonly the glands continue to secrete; they become increasingly distended with retained secretion, while the lining epithelium, at first columnar, becomes cuboidal, and later flat from pressure. In some cases the epithelium may be unrecognizable as an intact layer. In this way a number of cystic spaces-Nabothian folliclesare formed in the substance of the cervix, and often form projections, especially under the raginal aspect. In some extreme cases the cervix may be largely occupied by these cysts, but usually they are few in number. It will be evident, then, that the presence of Nabothian follicles indicates an advanced stage of the healing process in this condition, and that when these follicles have developed the red erosion will have disappeared, although fibrosis and puckering of the cervix usually persists.
In other cases the squamous epithelium may grow downwards into the glandular acini, which may become fully occupied by these squamous plugs. Unless this process is recognized these plugs of squamous cells filling the glands may present the appearance of columns of epithelioma, and an unnecessarily grave prognosis be given.

The final structural result, then, to the cervix consists of fibrosis and eversion, with some persistent Nabothian follicles.

\section{Late Results of Cenvicitis.}

The sequelae of the condition may now be considered. They are many and important, and may be grave. The parametrium is frequently affected by Jymphatic extension from the cervix, so that in the early stages tender infiltration and in later stages fibrosis is produced. The bases of the broad ligaments are often affected in this way, and frequently a tight fibrous scar can be felt stretching over one or other fornix from the edge of an eroded laceration. Equally often the utero-sacral ligaments are involved, and, on pulling the cervix forwards, pain in the lower part of the back is elicited.

These parametrial extensions are the most common eauses of backache or chronic pelvic pain in women.

Absorption of toxins from the chronically inflamed ces ricul surface leads in some cases to a degree of general ill health, and it is probable, as shown by clinical experience, that some cases of muscular rheumatism and osteoarthritis are due to such toxic absorption. Young 6 has recently cited examples of these complications, and $\mathbf{I}$ have also had experience of several cases which benefited largely by repair or amputation of the cervix. The presence of a continual vaginal discharge, again, may cause definite mental distress, but its effect in bringing about mental disease has probably been exaggerated. Sterility, and a tendency to puerperal sepsis, have been described as complications of this condition, but clinical experience does not bear this out. The majority of these patients have had a number of children, and when their labours have been normal no special tendency to pyrexia has been noted.

Direct extension to the uterine nucosa is not conmon, but as the lymphatics of the cervix and body are associated, chronic infection of the musculature of the uterus may occur, and the condition of chronic metritis develop. The main symptom here is menorrhagia with uterine enlargement, and this always indicates uterine involvement. Menorrhagia is not a symptom of uncomplicated cervical infection. In the same way, by lymphatic extension, th. tubes and ovaries are commonly affected, and chronic salpingo-oöphoritis may be produced, with resulting pelvic pain and sterility.

On account of prolonged lencorrhoeal discharge pruritus vulvae may develop, while in gonorrhoeal cases piolonged vulval irritation may produce a crop of irritating condylomata.

But the most important sequel is carcinoma. It is often a late sequel, occurring many years after the injury was inflicted. Carcinoma of the cervix usually occurs in patients who have had a child or children, and it is just these women who have had cervical damage and erosion. In. this connexion Farrar $^{3}$ recently reported that of 300 cases of carcinoma 96 per cent. had had one or more children. Similar figures are quoted by other writers, and $\mathrm{my}$ own experience is in general agreement with this.

So far as is known there is no marked tendency for the patient with the congenital erosion or the nullipara with the gonorrhoeal erosion to develop carcinoma, so we are forced to the conclusion that it is not merely the erosion, but the damage to the cervix at childbirth associated with the erosion, which is the predisposing factor in this connexion. This is borne out by the fact that most patients with carcinoma of the cervix have not had one but several pregnancies.

When we consider the long-continued irritation, the great epithelial probiferation which is stimulated, and tho damage, often repeated, of childbirth, the wonder is that carcinoma is not a more common sequel than is the case.

Carcinomatous overgrowth usually occurs in the squamous epithelium, and the first thing noticed is that the basal germinal layer proliferates in columns and breaks through its basement membrane. The cell columns penetrate 
decply into the substance of the cervix, and even before surface ulceration occurs a well-marked lymphocytic barrier is thrown out in an attempt, usually vain, to control the proliferating cells. Similar changes may occur in connexion with the glandular epithelium. When extensions occur, it is very common to find them most marked in the utero-sacral ligaments or along the thickened base of one or other broad ligament, the very places that have been previously affected by chronic irritative fibrosis.

\section{Conclusion.}

A study of this pathology shows us that the cervix is one of the most important pelvic structures and that chronic inflammation here is a widespread condition which may have far-reaching immediate and late results.

Another important point emerges that, while severe puerperal sepsis accompanied by pyrexia occurs in about four cases per thousand, puerperal sepsis in a minor degree, often with no symptoms at the time, lasting many years, and with a risk of carcinoma formation, occurs in a large proportion of all parturient women.

The main etiological factor in this condition is injury at childbirth, and these cervical injuries represent the wounds which women in labour receive in the process of producing the next generation.

The medical and sociological considerations raised by a study of this subject are very large and important, and there is no aspect of obstetrics and gynaecology which is more worthy of our attention.

Leucorrhoea may be produced by other lesions, such as tuberculous or syphilitic cervical ulcers, or foreign bodies, but only the more common lesion can be discussed in this paper.

REFERENCLS.

1 Bailey, K. V.: British Medical Jourual, 1929, i, 767 (ahstract) Bailey, K. V.: British Medlical Journal, 192.9, i, 767 (abstract).
Eden and Lockyer : Gynaccology, third edition, Lonclon, J. and A.
Churchill.

3 Farrar, Lilian K. P. : Surg., Gynecol. and Obstet., December, 1926, 4 Moench, G. L. : Amer. Journ. Obetet. and Gynecol., xi, 1926, 453

- Watson, B. P.: Eden and Lockyer's New System. of Ciynaecology, Goung, James : British Medical Journal, 1929, i, 891

\section{TREA'TMENT OF CHRONIC ENDOCERVICITIS.*}

R. S. STATHAM, O.B.E., M.D., Ch.M., HONORARY GYNAECOLOGIST, BRISTOL ROYAL INFIRMARY; LECTURER IN OBSTETRICS, UNIVERSITY OF BRISTOL; MEDICAL OFFICER IN VENEREAL DISEASE CLINIC, BRISTOL.

Whex I was asked if $I$ would open a discussion on the treatment of chronic endocervicitis at this mecting, $I$ felt much flattered at the honour done to me, but I accepted with grave misgivings when I came to consider the subject which had been assigned to me. I do not think there is any gynaecological condition which is seen so frequently by cloctors in all types of practice, and which is more diftirult to treat satisfactorily. It is presumably on account of this difficulty that the methods of treatment advised are so numerous and diverse; owing to this $I$ am unable to put forward any authoritative bibliography, and this paper expresses merely my own personal preferences.

That the condition requires treatment, and effectual treatment at that, is obvious when its complications are considered. Quite apart from the personal discomfort and annoyance which chronic leucorrhoea causes to patients of cleanly habits, it bears in its train a series of sequelae of great importance. It is one of the commonest causes of sterility and-perhaps even more often-of the one-child marriage. Again, owing to the deep ramifications of the glands of the endocervix, and their close relationship to the lymphatics draining into the base of the broad ligaments, it is a very common cause of a mild thickening and inflammation of the pelric cellular tissues in that region. This condition is very much commoner than is generally realized, and gives rise to pressure on, and nipping of, the ureter, with symptoms of chronic

${ }^{*}$ Read in opening a discussion in the Section of Obstetrics and Ginaecology at the Annual Meeting of the British Medical Association, Manchester, 1229. backache and renal pain. This has been most clearly worked out and described in numerous papers by Gui Hunner, ${ }^{4}$ and for some years $I$ have been in the habit of passing acorn-headed ureteric bougies up the ureters in cases of backache associated with "erosion," and it is astonishing how of ten there is found a well-defined stricture of the ureter about the situation where it passes across the cervix below the uterine artery. The worst complication which can ensue is carcinoma of the cervix, and $I$ am sure it is generally agreed that there is now no question as to the close relationship between the incidence of chronic infected lacerations and cancer of the cervix; so that if there were no other reasons at all, this fact alone would justify any attempt at curing these infections. It is not my province to discuss the pathology of this condition, but when it is reviewed it will be seen that there are two factors to be treated: (1) the leucorrhoea and so called crosion; (2) the deep infection of the cervical tissues with its surrounding infiltration. The former is much easier to attack and conquer than is the latter when once it is well established, and I would press for the early treatment of all lacerations of the cervix, and also for all established "crosions." This particularly applies to lacerations diagnosed at the time of tho confinement, which can easily be sutured immediately, or before the puerperium is concluded. De Lee ${ }^{2}$ states in his textbook that he has never seen a carcinoma follow on a laceration which has been properly repaired at the time when it occurred.

Although leucorrhoea may be one of the symptoms of a variety of gynaecological conditions this paper is concerned only with chronic infection of the endocervix, and no attempt is made to discuss the diagnosis or treatment of any of the other conditions giving rise to similar symptoms.

Coming now to the actual treatment of the condition of chronic endocervicitis, when it is established, we are at once faced with the problem of the individuality of the patient. It is impossible to apply the same rules of treatment to the patient with an extensive laceration as to the one with no tear at all. It is equally useless to group together the young woman with an infection following her first childbirth and the patient of 55 who will not become pregnant again. Each case must be considered on its merits, and to some extent the cause of the lesion will direct the method of its cure.

For some years I have had the great advantage of being on the staff of the Bristol renereal clinic as well as being gynaecologist to the Royal Infirmary, and I am firmly convinced that gonorrhoea is far more commonly at the bottom of a chronic cervical infection than is usually thought. In my gynaecological out-patient clinic smears are taken from the urethra and cervix of all cases of leucorrhoea, and quite a large proportion are returned showing gonococci present, when the case is transferred to the venereal disease clinic for treatment. The converse also holds good. I have now seen a very large number of cases of gonorrhoea which have developed erosions of the cervix while under treatment, and this condition persists when no trace of the gonococcus can be obtained with the most careful methods of taking smears and cultures. I would like to stress the importance of paying no attention to the presence or absence of a discharge in deciding as to whether a gonorrhoea is cured, because the leucorrhoea associated with the resulting chronic endocervicitis will persist for a rery long time after the actual gonococcal infection is cured. It is therefore, in my opinion, necessary to examine all cases of chronic cervical infection for gonococci-by smears from urethra, cervix, and Bartholin's glands-before commencing further treatment.

If the presence of the gonococcus can be demonstrated I consider that there is no treatment so good as that of daily donching with boric acid, wiping away the mucopus, and then thoroughly swabbing the cervix and vaginal vault with 1 per cent. mercurochrome. ${ }^{9}$ I think the stronger solutions defeat their object by delaying the normal process of healing - that is, the replacement of the columnar-celled erosion by the normal squamous-celled covering of the raginal surface of the cervix. In all 